\title{
The risks and benefits of social media in dental foundation training
}

\author{
S. Bhola*1 and P. Hellyer ${ }^{2}$
}

\section{In brief}

Defines and explores social media and its uses in dentistry.
Discusses the advantages and disadvantages of social media, and how it could be used to improve learning in dental foundation training.
Encourages safe use of social media for all dental care professionals, and for Dental Foundation Trainees in particular.

The use of social media has greatly expanded in the last decade, with widespread use of smartphones, the internet, and other multimedia to enhance learning. There is evidence to suggest that social media has a place in healthcare education, but there is limited research to suggest the effectiveness or use of it in dental foundation training. This paper discusses the risks and benefits of social media and suggests that a better understanding of social media and its role in the development and practice of newly qualified dental professionals could benefit both trainees and trainers.

\section{Introduction}

Social media, also known as 'Web 2.0' or 'social networking ${ }^{1,2}$ has been defined in many ways. General consensus from the literature states that social media is 'computer mediated' and enables people to exchange information. ${ }^{3}$ Balakrishnan defines social media as follows: 'social media generally allows users to create, share, and exchange data with others. Social media services such as Facebook, Twitter, and YouTube allow people from diverse backgrounds to express themselves and connect with other users across the world. ${ }^{4}$ Further definitions have also been given by Solis, ${ }^{5,6}$ and Selwyn. ${ }^{7}$ Common themes include:

- Social media involves the collaboration and interaction of many users

- Most of these interactions happen online via audio, visual and textual content

- It involves a sense of community, rather than individuals. ${ }^{8}$

'Dental Core Trainee, Oral and Maxillofacial Surgery, Princess Alexandra Hospital, Harlow, CM20 1QX; ${ }^{2}$ Honorary Teaching Fellow, University of Portsmouth Dental Academy, Hampshire Terrace, Portsmouth P01 2QG

${ }^{*}$ Correspondence to: S. Bhola

Email: surina.bhola@hotmail.com

Refereed Paper. Accepted 15 September 2016

DOI: 10.1038/sj.bdj.2016.854

${ }^{\circ}$ British Dental Journal 2016; 221: 609-613

Table 1 Glossary of terms ${ }^{1,10,11}$

\begin{tabular}{l|l} 
Term & Definition \\
\hline App & $\begin{array}{l}\text { A software application developed specifically for use on small, wireless computing } \\
\text { devices, such as smartphones and tablets, rather than desktop or laptop computers }\end{array}$ \\
\hline Blog & $\begin{array}{l}\text { An interactive website, or part of a website, maintained by an individual, a group of } \\
\text { individuals, or an organisation that posts regular entries of commentaries and events. }\end{array}$ \\
\hline Microblog & A web service that allows subscribers to send short messages to other subscribers. \\
\hline Tweet & A Twitter message, which by definition must be no more than 140 characters. \\
\hline
\end{tabular}

The General Dental Council (GDC), the main regulatory body for dental professionals in the UK, defines social media as follows: 'Social media covers a number of internet based tools including, but not limited to, blogs, internet forums, content communities and social networking sites such as Twitter, YouTube, Facebook, LinkedIn, GDPUK, Instagram and Pinterest. Professional social networking websites aimed solely at dental professionals are also forms of social media. ${ }^{9}$

In view of the risks posed by the use of social media, this definition will be the one used in this opinion paper. The GDC sets the standards to which all registered dentists and dental care professionals in the UK must adhere. Further definitions of terms often used when discussing social media are given in Table $1 .^{10-12}$

Dental foundation training (DFT) is a training year to prepare newly qualified dentists for primary care and independent practice, through supervised teaching and education. Having an experienced trainer or 'educational supervisor' aims to ensure high standards of patient care, as well as providing guidance to new trainees, and a foundation for future practice. ${ }^{13,14}$

This opinion piece provides a brief overview of the social media platforms commonly available, the value of social media to the profession, and a discussion of the risks and benefits to newly qualified dental professionals.

\section{Increasing popularity of social media}

Public attitude towards social media has changed significantly in recent years as it has become more diverse and accessible. ${ }^{1517}$ Sites such as Instagram, Twitter and YouTube have millions of users. 
Statistically, $52 \%$ of adults used two or more social media sites in 2014, compared to $42 \%$ in $2013 .{ }^{18}$ In 2015 , this increased to $61 \% .{ }^{19}$ However, there is evidence to suggest generational discrepancy in use, ${ }^{15,17}$ with younger generations having a greater online presence..$^{20}$ In 2015, 88\% of 16-24-year-olds used social media daily, compared to $60 \%$ aged 65 and older. ${ }^{19}$

\section{What does the GDC say?}

The GDC sets standards for UK dental professionals. Paragraph 4.2.3 of the Standards for the dental team states: 'You must not post any information or comments about patients on social networking or blogging sites. If you use professional social media to discuss anonymised cases for the purpose of discussing best practice you must be careful that the patient or patients cannot be identified.'

It is imperative that dental professionals gain valid consent from patients where they are posting patient specific information. The GDC is clear that all online discussions, images and media should be anonymised and to ensure no patient information is included in these without consent. If this is followed, social media allows a rapid and effective way of gaining opinions from a large community of professionals. A summary of the guidance set is shown in Box $1 .^{9}$

\section{Social media in dentistry}

Using the interfaces mentioned below, searches were carried out by entering key words, such as 'dentistry' and 'oral surgery' into the search bars, then explored to see what resources were available that may be used by a foundation trainee. Literature searches were carried out using Google Scholar, EMBASE, and PubMed databases.

\section{Facebook}

The Pew Research Centre has reported two thirds of adults online use Facebook, ${ }^{15,18}$ with more than 1 billion active users worldwide. ${ }^{20}$ During an online search, Facebook has many groups for dentists, including 'For Dentists, by Dentists', groups for individual marketing, as well as pages for associations such as the Faculty of General Dental Practice UK (FGDP[UK]) and British Academy of Cosmetic Dentistry (BACD). In both of these, there are social networking links to other forms of social media, and opportunities to sign up for membership,

Box 1 Updated summary of guidance on using social media by the

\section{General Dental Council ${ }^{9}$}

\section{Summary of social media guidance}

Behave professionally both online and offline

Do not publish information which could identify patients on social media without consent

Information must comply with the employer's social media policy

Professionals must maintain appropriate boundaries with patients, and think carefully before accepting friend requests from patients

Professionals must not instigate or take part in any form of cyber bullying, intimidation, or use of offensive language, including sharing inappropriate content posted by someone else

Professionals should not post any information, including personal views, photos or videos which could damage public confidence in the profession.

which allows for networking, links to learning materials, courses and forums. ${ }^{21,22}$

The British Dental Association (BDA), which also has a Facebook presence, is the professional trade union and association for dentists in the UK. ${ }^{23}$ As well as an online website, the BDA has a corresponding mobile 'app', for which membership is required. Once a member, it provides a huge database of education material, a blog, expert opinion and advice, and links to the British Dental Journal. ${ }^{23}$

\section{Instagram}

Instagram currently has about 500 million active users. ${ }^{24}$ It is mainly a mobile app which enables users to capture pictures or short videos, which they can share to other Instagram followers, as well as linking to other forms of social media, such as Facebook. When the term 'dentistry' was searched, examples of results included bloodytoothguy, which focused on videos related to oral surgery, and dentistrymyworld, which has a combination of educational videos and photographs of complex multidisciplinary cases.

\section{Twitter}

Twitter is a microblog ${ }^{25}$ which allows users to post short messages, or 'tweet' which can be read by other Twitter users. Users can declare who they wish to 'follow', in which case they receive updates every time that user posts any information. ${ }^{26}$ During the search, Twitter has been proven to be a large database, where photographs, videos, and discussions and forums are displayed.

\section{YouTube}

YouTube is a video sharing site, which allows users to view, post, and comment on digital media content at no cost. ${ }^{1,2}$ There are also opportunities for private messaging and networking. This, as with many other forms of social media, is accessible on mobile and tablet devices. Moreover, there seems to be an increase in the number of institutions making their own media contributions via YouTube channels, for educational purposes. During the research, there was a vast database of educational videos on a wide range of topics, as well as patient communication tools, which was easily accessible by entering 'key words' into the search bar. Again, this is not refereed or evidence based.

\section{Pinterest}

Pinterest has gained growing popularity being a 'pin board' style website, where images can be shared and 'pinned. ${ }^{27}$ It now has over 11 million users, and can be used on a PC or synced to a mobile app. A study by Guidry showed that visitors spent more time on Pinterest (14.2 minutes) than on other social media platforms. ${ }^{28}$ In the search tabs, 'dental', and 'oral surgery' were entered. From this, many images and diagrams were accessed, such as of dental instruments, as well as resources for patient education.

\section{Social networking sites}

\section{GDPUK}

This website (www.gdpuk.com) reports over 130,000 visits each month, with over 35,000 unique visitors each month. ${ }^{29}$ Although registration is required for full access, once this stage is complete, there is a vast array of access to CPD (continuing professional development) material, CQC (Care Quality Commission) updates, and an option to contact the website for queries. Members also gain updates to local events, as well as access to a number of discussion forums. This website also links to other forms of social media such as Twitter and Facebook. 


\section{Linkedln}

LinkedIn is a form of social media largely catered towards professional recruitment, with a focus on a more professional audience ${ }^{30}$ as well as self-promotion. ${ }^{31}$ Jeff Weiner, the CEO of LinkedIn, stated: 'LinkedIn is a professional network... The key distinction is that as a professional you want people to want to know who you are...'

Once subscribed, the website allows uploading of a personal profile for professional networking and employment opportunities, and automatically identifies mutual friends or colleagues known to the profession. There is a corresponding mobile app for this. Relating this to the dental profession, LinkedIn provides the contact details for colleagues, and clinicians in the same field, which may be useful for networking for newly qualified dentists.

\section{Other}

Other forms of social media include the social networking site 'ResearchGate', which allows academics to create their own profiles, interact with each other, as well as document the publications they have been involved with. Members can also upload their publications onto the websites database, which can increase accessibility. Evidence has also suggested that, as ResearchGate allows access to numbers of views and downloads to the publisher, it may provide information to the author about the popularity of their publications. ${ }^{32}$

In addition, blogs created by dentists, such as atoothgerm, have posts catered towards foundation trainees, as well as clinical tips and personal experiences. Many other social media sites exist, such a Tumblr, Whatsapp and Snapchat, all of which encourage digital communication between users.

However, those mentioned above are those which have impacted the working life of one of the authors (SB) the most.

\section{Opportunities in social media}

\section{Professional networking}

Social media allows links to the professional community, which can provide much needed support, feedback and education to clinicians. ${ }^{33}$ Dental school is very much a social environment, which may be in stark contrast to the potential loneliness of dental foundation training, as well as general practice life - up to $55.4 \%$ of dentists at some point have felt lonely. ${ }^{34}$ It has been seen that 'belongingness' is very important in undergraduate training, and students benefit both educationally and socially from being part of a well-respected 'dental learning environment', setting them up for autonomy after qualification. ${ }^{35}$ In this context, social media may help to increase 'belongingness' in foundation year, as it allows regular opportunities for social and professional interaction. The use of social media may, therefore, ease the transition from university to a more isolated practice environment, by providing an easy to use communication platform which is available 24 hours a day.

\section{Education}

To a foundation trainee, social media provides a large array of educational material, not only from more experienced clinicians, but from fellow trainees. It has become more easily accessible and can be utilised using a variety of media, such as tablets or smartphones. This can help to broaden horizons of trainees, as well as aid lecturers, teachers, and clinical supervisors in delivering information to trainees.

The value of social media as an educational tool has been described previously. It can also allow members not to feel discriminated or confined by any disciplinary action, and share experiences in a social environment, comparing and contrasting experiences from peers. ${ }^{1}$ It has also to be recognised that the majority of the educational content is available at no cost to the user, an important consideration to recent graduates qualifying with large student debts.

\section{Promotion}

Social media has shown to be widely used in self and business promotion, to develop a 'digital voice.. ${ }^{33}$ For example, LinkedIn can provide accessible information about career options and pathways, as well as employment opportunities. ResearchGate is also very useful in promoting publications, as well as interacting with colleagues. ${ }^{32}$ There is evidence to suggest the use of social media in practice promotion and advertisement. Henry et al. ${ }^{36}$ conducted a study of dental practices in 2012 in the USA, and reported that $51 \%$ of practices used social media, of which $91 \%$ was for marketing, and $73 \%$ to increase their online presence.

By contributing to discussions on forums available at, for instance, GDPUK, the newly qualified practitioner is raising their profile among a group of more experienced practitioners, many of whom may be geographically distant. The opportunity to network among those groups of colleagues, whom they are unlikely to meet in any other circumstance, can be invaluable.

\section{Risks of social media}

\section{Poor quality of information}

As a dental professional, it is imperative to understand the evidence base, or lack of the information we access. This is a significant disadvantage of using social media for learning, as it is difficult to ascertain the validity of the information given. ${ }^{1,37-39}$ Examples may include poorly referenced information, lack of evidence base, as well as the fact that any user can upload content to any website. . $^{1,37-39}$

The different raisons d'etre of websites should be recognised. Some, such as the BDA or FGDP(UK), are primarily educational. Others, such as those selling specific technologies or techniques, are set up on a more commercial basis and less likely to provide a discussion of a broad range of alternatives. A study by Chumber et al. discussed the usage of validity tools such as the 'JAMA' accreditation. ${ }^{40}$ As nothing like this is currently available for platforms such as Twitter and Facebook, users must be wary of the information that is read.

\section{Damage to professional image}

The General Dental Council has established clear guidelines that all dental professionals should never post information demeaning to the profession as a whole. ${ }^{9}$ Although social media enables dentists to converse freely and sometimes anonymously, users must be diligent not to post any inappropriate or potentially harmful material which could be detrimental to their own reputation and that of the profession as a whole. (Box 1)

\section{Consent and legal issues}

As clearly outlined by the GDC, all patient related information should be anonymised. However, once information is posted, it is very difficult to retract, and if discovered, could lead to disciplinary action. ${ }^{1}$ This is why it is important, especially as a trainee, to establish a professional online etiquette from the beginning, gaining relevant written consent, and not allowing patient identifiable information to be shared via social media., ${ }^{1,41.42}$

Dentists who interact with their patients on social interfaces may be violating the patienthealth care professional boundary. ${ }^{1}$ As a young dentist, communication through social platforms is more common than for older 


\section{Box 2 Tips for staying safe on social media}

\section{Staying safe on social media}

Always follow the proper guidelines set by the GDC, and always take the proper consent if posting any patient information, anonymising details

Always refer to patients with respect, and never post any information or comments which portray a negative view of the profession

Make sure information shared is from credible sources, and evidence based

Acknowledge any incorrect information encountered

Respect copyright issues, adding a disclaimer of any information shared

Avoid advising patients on forms of social media

Keep your personal and professional networking separate - if a patient wishes to join your network, direct them to your professional site

Always state your credentials on professional sites, and if you are representing an employer

\section{Box 3 How to gain the most from social media}

\section{Gaining the most from social media}

Network early with other members of the community after graduation

Determine areas of special interest, and follow these pathways on social media

Subscribe to channels and pages and receive email and social media updates

Always keep updating your profile, and constantly seek out new information

clinicians, so this is a real risk for trainees. Online discussions between patients and healthcare professionals can introduce legal complexities and lawsuits, ${ }^{42}$ especially if inappropriate comments are made. This has been shown in the United States, where physicians making comments about patients on Facebook have led to disciplinary action. ${ }^{42} \mathrm{~A}$ recent letter to the $B D J$ suggests that about one third of dentists responding to a small poll were willing to accept friend requests from patients on Facebook. ${ }^{43}$

\section{Discussion}

As a recently qualified dentist, the first author (SB) considers that more signposting to social media sites of interest would have been helpful during the foundation year. Groups such as 'For Dentists, by Dentists', where clinicians openly discuss difficult cases, were particularly beneficial. Responses give a wide variety of opinions from general dental practitioners, specialists, and consultants. However, being an open forum, there are sometimes differing trains of thought. As a trainee, the best way to get a valid opinion is to always query the evidence base behind the opinion, which many of the clinicians online are happy to provide, sometimes with links to the literature. Sites such as Facebook have allowed maintenance of professional contacts post-graduation, and these can be used for obtaining guidance and research support.
Moreover, viewing high quality treatment from senior clinicians on platforms such as Instagram and Pinterest can provide inspiration for a newly qualified dentist. Social media is expected to expand vastly over the forthcoming years with an ever-growing plethora of media sources, apps and devices targeted towards education, business and marketing. ${ }^{1,15,17,27}$

Sites such as GDPUK do not promote themselves to newly qualified dentists. It can be very daunting to join in an online discussion with more senior colleagues. Their strongly held opinions, expressed in print format, can be taken personally by the less experienced and confidence damaged. However, social media offers a wide range of learning opportunities. For visual learners, for instance, video sharing forms of social media, particularly YouTube, can be extremely beneficial. This is supported by a study by Grajales et al. ${ }^{44}$ who postulated that video sharing websites will most likely increase for education, as they are available to all learners $24 / 7$. This study revealed that these types of visual websites offer new educational possibilities, but are 'underdeveloped and underestimated regarding their potential value. ${ }^{34}$

Other forms of social media such as LinkedIn and Researchgate may be useful in expanding individual professional networks and allowing for self-promotion, and in the case of LinkedIn, searching for jobs, not only locally, but internationally on completion of foundation training. For their foundation year, dentists are allocated a more experienced educational mentor. It is possible that they may not be as experienced with using social media, as they may have learnt from more traditional forms of learning, such as lectures. Foundation trainees also have more traditional forms of teaching available on their study days, but would benefit from a combination of teaching methodologies.

Safe use of social media is of paramount importance to all health care professionals, but the newly qualified may be at particular risk. Box 2 summarises some important points about self-protection in the use of social media. Box 3 gives some tips on how to get the best from social media sites.

\section{Conclusion}

Social media can be a key tool in enhancing education. It is our opinion that social networks are an invaluable and under-utilised educational resource, for trainees and more experienced clinicians alike. If proper guidelines (such as those proposed by the GDC) are followed, there is no reason why social media cannot be an economical and an integral part of learning and development, enhancing collaboration between health professionals, and developing a sense of community.

A special thank you to Dr David Radford (Reader, King's College London, and University of Portsmouth Dental Academy) for his guidance throughout the development of this paper.

1. Ventola C L. Social media and health care professionals: benefits, risks, and best practices. PT 2014; 39: 491.

2. McAndrew $M$, Johnston A E. The role of social media in dental education. J Dent Educ 2012; 76: 1474-1481.

3. Pilcher J, Harper M. Engaging learners with social media. J Nurses Prof Dev 2016; 32: 137-143.

4. Balakrishnan V, Gan C L. Students' learning styles and their effects on the use of social media technology for learning. Telematics and Informatics 2016; 33: 808-821.

5. Solis B. The essential guide to social media. Available at: https://www.scribd.com/document/3283966/The-Essential-Guide-to-Social-Media (accessed July 2016).

6. Solis B, Carroll B. Customer service: the art of listening and engagement through social media. Business, 7 March 2008.

7. Selwyn N. Social media in higher education. pp 1-10. The Europa World of Learning, 2012.

8. Shirky C. Here comes everybody: The power of organizing without organizations. Penguin, 2008.

9. General Dental Council. Guidance on using social media Effective from 27 June 2016. Available at: http://www. gdc-uk.org/Dentalprofessionals/Standards/Documents/ Guidance \%20on\%20using\%20social\%20media.pdf (accessed October 2016).

10. Grajales III F J, Sheps S, Ho K, Novak-Lauscher H, Eysenbach $G$. Social media: a review and tutorial of applications in medicine and health care. J Med Internet Res 2014; 16: e13.

11. Dizon D S, Graham D, Thompson M A, Johnson L J, Johnston C, Fisch M J, Miller R. Practical guidance: the use of social media in oncology practice. J Oncol Pract 2012; 8: e114-124.

12. Whatls.com. Defintion: mobile app. Available at: http:// whatis.techtarget.com/definition/mobile-app (accessed July 2016). 
13. Gallagher J E, Clarke W, Eaton K A, Wilson N H. Dentistry - a professional contained career in healthcare. A qualitative study of Vocational Dental Practitioners' professional expectations. BMC Oral Health 2007; 7: 16.

14. Prescott L E, McKinlay P, Rennie J S. The development of an assessment system for dental vocational training and general professional training: a Scottish approach. $\mathrm{Br}$ Dent J 2001; 190: 41-44.

15. Lenhart A, Purcell K, Smith A, Zickuhr K. Social media $\&$ mobile internet use among teens and young adults. Millennials. Pew Internet \& American Life Project, 3 February 2010

16. Duggan M, Smith A. Social media update 2013 [PewResearch Internet Project].

17. Davis III C H F, Deil-Amen R, Rios-Aguilar C, Canche M S G. Social media in higher education: A literature review and research directions. [Unpublished paper] 2012. Available at: https://works.bepress.com/hfdavis/2/ (accessed October 2016)

18. Duggan M, Ellison N B, Lampe C, Lenhart A, Madden M. Social media update 2014. p 9. Pew Research Center, 2015.

19. Office for National Statistics. Household engagement - C12: Use of the Internet for participating in social networks. Available at: http://webarchive.nationalarchives. gov.uk/20150909074951/http://www.ons.gov.uk/ons/ guide-method/method-quality/specific/business-andenergy/e-commerce-and-ict-activity/social-networking/ index.html (accessed November 2016).

20. Westrick S J. Nursing students' use of electronic and social media: law, ethics, and e-professionalism. Nurs Educ Perspect 2016; 37: 16-22.

21. Faculty of General Dental Practice UK. Online information available at http://www.fgdp.org.uk. (accessed July 2016).
22. British Academy of Cosmetic Dentistry. Online information available at https://bacd.com. (accessed July 2016).

23. British Dental Association. Online information available at https://www.bda.org. (accessed July 2016)

24. Instagram Press Centre. Online information available at http://instagram.com/press (accessed July 2016).

25. Kwak H, Lee C, Park H, Moon S. What is Twitter, a social network or a news media? In Proceedings of the 19th International Conference on World wide web 2010 (pp 591-600). ACM.

26. Huberman B A, Romero D M, Wu F. Social networks that matter: Twitter under the microscope. Available at Social Science Research Network 1313405. 2008.

27. Hansen K, Nowlan G, Winter C. Pinterest as a tool: Applications in academic libraries and higher education. Partnership: The Canadian Journal of Library and Information Practice and Research 2012; 7.

28. Guidry J P, Carlyle K, Messner M, Jin Y. On pins and needles: how vaccines are portrayed on Pinterest. Vaccine 2015: 33: 5051-5056.

29. GDPUK. Online information available at http://www. gdpuk.com (accessed July 2016).

30. Van Dijck J. 'You have one identity': performing the self on Facebook and LinkedIn. Media, Culture \& Society 2013; 35: 199-215.

31. McCorkle D E, McCorkle Y L. Using LinkedIn in the marketing classroom: Exploratory insights and recommendations for teaching social media/networking. Marketing Education Review 2012; 22: 157-166.

32. Thelwall M, Kousha K. ResearchGate: Disseminating communicating, and measuring scholarship? J Assoc Info Sci Tech 2015; 66: 876-889.

33. Hatzipanagos S, John B, Chiu Y L. The significance of kinship for medical education: Reflections on the use of a bespoke social network to support learners' profes- sional identities. JMIR Med Educ 2016; 2: e1.

34. Puriene A, Aleksejuniene J, Petrauskiene J, Balciuniene I, Janulyte V. Self-perceived mental health and job satisfaction among Lithuanian dentists. Industrial Health 2008; 46: 247-252.

35. Radford D R, Hellyer P. Belongingness in undergraduate dental education. Br Dent J 2016; 220: 539-543.

36. Henry R K, Molnar A, Henry J C. A survey of US dental practices' use of social media. J Contemp Dent Pract 2012; 13: 137-141.

37. Kravitz R L. Social media: new opportunities, new ethical concerns. J Gen Intern Med 2013; 28: 165.

38. Lambert K M, Barry P, Stokes G. Risk management and legal issues with the use of social media in the healthcare setting. J Healthc Risk Manag 2012; 31: 41-47.

39. George D R, Rovniak LS, Kraschnewski J L. Dangers and opportunities for social media in medicine. Clin Obstet Gynecol 2013; 56: 453-462.

40. Chumber S, Huber J, Ghezzi P. A methodology to analyse the quality of health information on the internet. The example of diabetic neuropathy. Diabetes Educ 2015; 41: 95-105.

41. Farnan J M, Sulmasy L S, Worster B K et al. Online medical professionalism: patient and public relationships: policy statement from the American College of Physicians and the Federation of State Medical Boards. Ann Intern Med 2013; 158: 620-627.

42. Chauhan B, Janis Coffin D O FA. Social media and you: what every physician needs to know. J Med Pract Manage 2012; 28: 206-209.

43. Mc Crory P V, Jacobs A V. Social media: Friends with patients. Br Dent J 2016; 221: 49-50.

44. Grajales III FJ, Sheps S, Ho K, Novak-Lauscher H, Eysenbach $\mathrm{G}$. Social media: a review and tutorial of applications in medicine and health care. J Med Internet Res 2014; 16: e13. 